\title{
Cumulative burden of metabolic syndrome and its components on the risk of atrial fibrillation: a nationwide population-based study
}

Hyo-Jeong Ahn ${ }^{1+}$, Kyung-Do Han ${ }^{2+}$, Eue-Keun Choi ${ }^{1,3^{*}} \mathbb{D}^{\text {, Jin-Hyung Jung }}{ }^{4}$, Soonil Kwon ${ }^{1}$, So-Ryoung Lee ${ }^{1}$, Seil Oh ${ }^{1,3}$ and Gregory Y. H. Lip $3,5,6$

\begin{abstract}
Background: The metabolic syndrome (MetS) and its components are associated with the development of atrial fibrillation (AF). However, the impact of time-burden of MetS on the risk of AF is unknown. We investigated the effect of the cumulative longitudinal burden of MetS on the development of AF.

Methods: We included 2885189 individuals without AF who underwent four annual health examinations during 2009-2013 from the database of the Korean national health insurance service. Metabolic burdens were evaluated in the following three ways: (1) cumulative number of MetS diagnosed at each health examination ( $0-4$ times); (2) cumulative number of each MetS component diagnosed at each health examination (0-4 times per MetS component); and (3) cumulative number of total MetS components diagnosed at each health examination ( 0 to a maximum of 20). The risk of AF according to the metabolic burden was estimated using Cox proportional-hazards models.

Results: Of all individuals, 62.4\%, 14.8\%, 8.7\%, 6.5\%, and 7.6\% met the MetS diagnostic criteria 0, 1, 2, 3, and 4 times, respectively. During a mean follow-up of 5.3 years, the risk of AF showed a positive association with the cumulative number of MetS diagnosed over four health examinations: adjusted hazard ratios (HRs) with 95\% confidence intervals (Cls) of 1, 2, 3, and 4 times compared to 0 times were $1.18(1.13-1.24), 1.31(1.25-1.39), 1.46(1.38-1.55)$, and 1.72 (1.63-1.82), respectively; $P$ for trend $<0.001$. All five components of MetS, when diagnosed repeatedly, were independently associated with an increased risk of AF: adjusted HR (95\% Cl) from 1.22 (1.15-1.29) for impaired fasting glucose to 1.96 (1.87-2.07) for elevated blood pressure. As metabolic components were accumulated from 0 to 20 counts, the risk of AF also gradually increased up to 3.1 -fold (adjusted HR 3.11,95\% Cl 2.52-3.83 in those with 20 cumulative components of MetS), however, recovery from MetS was linked to a decreased risk of AF.
\end{abstract}

Conclusions: Given the positive correlations between the cumulative metabolic burdens and the risk of incident AF, maximal effort to detect and correct metabolic derangements even before MetS development might be important to prevent AF and related cardiovascular diseases.

Keywords: Metabolic syndrome, Metabolic burden, Atrial fibrillation

*Correspondence: choiek17@snu.ac.kr

${ }^{\dagger}$ Hyo-Jeong Ahn and Kyung-Do Han contributed equally to this work

${ }^{1}$ Department of Internal Medicine, Seoul National University Hospital,

101 Daehak-ro, Jongno-gu, Seoul 03080, Republic of Korea

Full list of author information is available at the end of the article

\section{Background}

Atrial fibrillation (AF) is the most common sustained cardiac arrhythmia associated with an increased risk of stroke, heart failure, myocardial infarction (MI), dementia, and death [1-3]. The prevalence of AF in adults is

(c) The Author(s) 2021. This article is licensed under a Creative Commons Attribution 4.0 International License, which permits use, sharing, adaptation, distribution and reproduction in any medium or format, as long as you give appropriate credit to the original author(s) and the source, provide a link to the Creative Commons licence, and indicate if changes were made. The images or other third party material in this article are included in the article's Creative Commons licence, unless indicated otherwise in a credit line to the material. If material is not included in the article's Creative Commons licence and your intended use is not permitted by statutory regulation or exceeds the permitted use, you will need to obtain permission directly from the copyright holder. To view a copy of this licence, visit http://creativeco mmons.org/licenses/by/4.0/. The Creative Commons Public Domain Dedication waiver (http://creativecommons.org/publicdomain/ zero/1.0/) applies to the data made available in this article, unless otherwise stated in a credit line to the data. 
$2 \%-4 \%$, and the lifetime AF risk was recently estimated as 1 in 3 individuals of European ancestry at an index age of 55 years $[4,5]$. As the incidence of AF is expected to increase, management of AF has been emphasized as integrating stroke prevention, symptom control, risk factors management, and lifestyle modification $[6,7]$.

Metabolic syndrome (MetS) is a cluster of metabolic disorders including glucose intolerance, low level of highdensity lipoprotein cholesterol (HDL-C), high level of triglyceride (TG), obesity, and hypertension [8, 9]. MetS, frequently combined with other atherosclerotic risk factors, has become a pandemic that increases the risk of cardiovascular morbidity and mortality $[8,10]$.

As both AF and MetS lead to significant cardiovascular diseases, imposing an enormous healthcare burden, many studies have attempted to reveal the relationship between MetS and AF development; MetS and its components are known to be associated with AF development $[11,12]$. Elevated levels of inflammation, oxidative stress, and mechanical stimuli to the atrium have been proposed as the underlying pathophysiology of AF development in MetS $[10,13,14]$. Also, insulin resistance has been identified as one of the common physiologic manifestations significantly associated with both AF and MetS [15-18]. Notably, Type 2 diabetes is a well-known independent risk factor of $\mathrm{AF}$, and one of the components of $\mathrm{CHA}_{2} \mathrm{DS}_{2}$-VASc-score used to identify high-risk $\mathrm{AF}$ patients for stroke $[19,20]$. However, MetS status and its components are variable as they can change over time dynamically. A recent study demonstrated the association between the exposure duration or extent of metabolic disturbances and the increased risk of MI and stroke, which are AF-related complications [21]. Nonetheless, to what extent the time-burden of MetS affects the risk of AF itself has not been evaluated. Therefore, we aimed to investigate the effect of the cumulative longitudinal burden of MetS on AF development through a nationwide population-based cohort analysis.

\section{Methods}

We defined a population-based cohort from the National Health Information Database (NHID) incorporating all data from the National Health Insurance Service, which covers the entire population of the Republic of Korea (hereafter, Korea). All insured adults aged 40 years and older are recommended to undergo biannual general health screening without cost [22]. Not only the regular health examination records, including laboratory results, anthropometric measurements, and detailed lifestyle questionnaires, but also sociodemographic data, incomebased insurance contributions, prescription records, inpatient and outpatient usage, and date of death of all insured Koreans are available in the NHID [22, 23]. The
Institutional Review Board at the Seoul National University Hospital (E-2009-091-1157) authorized this study.

We selected 3981515 adults aged $\geq 20$ years who underwent four serial health examinations between January 1, 2009, and December 31, 2013, from the NHID. Individuals with a prior history of AF and missing values of health examination data or covariates were excluded (Additional file 1: Fig. S1). Finally, 2885189 adults were included in the analysis.

\section{Evaluation of metabolic syndrome and the influence of cumulative metabolic burden}

MetS was defined using modified waist circumference (WC) criteria of the Korean Society for the Study of Obesity and the guidelines of the National Cholesterol Education Program Third Adult Treatment Panel (NCEP-ATP III) as the presence of $\geq 3$ of the following: increased WC $[\geq 90 \mathrm{~cm}$ in men or $\geq 85 \mathrm{~cm}$ in women], elevated TG $[\geq 150 \mathrm{mg} / \mathrm{dL}(1.7 \mathrm{mmol} / \mathrm{L})$ or drug treatment for elevated TG], low HDL-C $[<40 \mathrm{mg} / \mathrm{dL}(1 \mathrm{mmol} / \mathrm{L})$ in men and $<50 \mathrm{mg} / \mathrm{dL}(1.3 \mathrm{mmol} / \mathrm{L})$ in women or drug treatment for low HDL-C], elevated blood pressure [systolic blood pressure $\geq 130 \mathrm{mmHg}$ or diastolic blood pressure $\geq 85 \mathrm{mmHg}$ or current use of antihypertensives], and impaired fasting glucose [fasting plasma glucose $\geq 100 \mathrm{mg} / \mathrm{dL}(5.6 \mathrm{mmol} / \mathrm{L})$ or current use of antidiabetics] $[8,9,24]$.

At each health examination, the presence of MetS itself and the number of fulfilled components of MetS were calculated. "Metabolic burden" is defined as the following three multifaceted ways during four health examinations: (1) cumulative number of MetS diagnosed at each health examination (0-4 times); (2) cumulative number of each MetS component diagnosed at each health examination (0-4 times per each MetS component); and (3) cumulative number of total MetS components diagnosed at each health examination ( 0 to a maximum of 20 ). The overall scheme of the study and the three different ways of defining metabolic burdens are shown in Fig. 1a.

To estimate the influence of temporal trends in metabolic burden on AF incidence, we compared the number of metabolic components at the first health examination with that at the last examination. The total study population was divided into two groups according to the change in the number of metabolic components (Fig. 1b).

Group A was defined as the group with a decrease in the number of metabolic components, whereas group B was defined as that with an increase or maintenance in the number of metabolic components at the last health examination compared to that in the first examination. We stratified groups A and B according to the total number of MetS components diagnosed during the four health examinations. At each cumulative number 


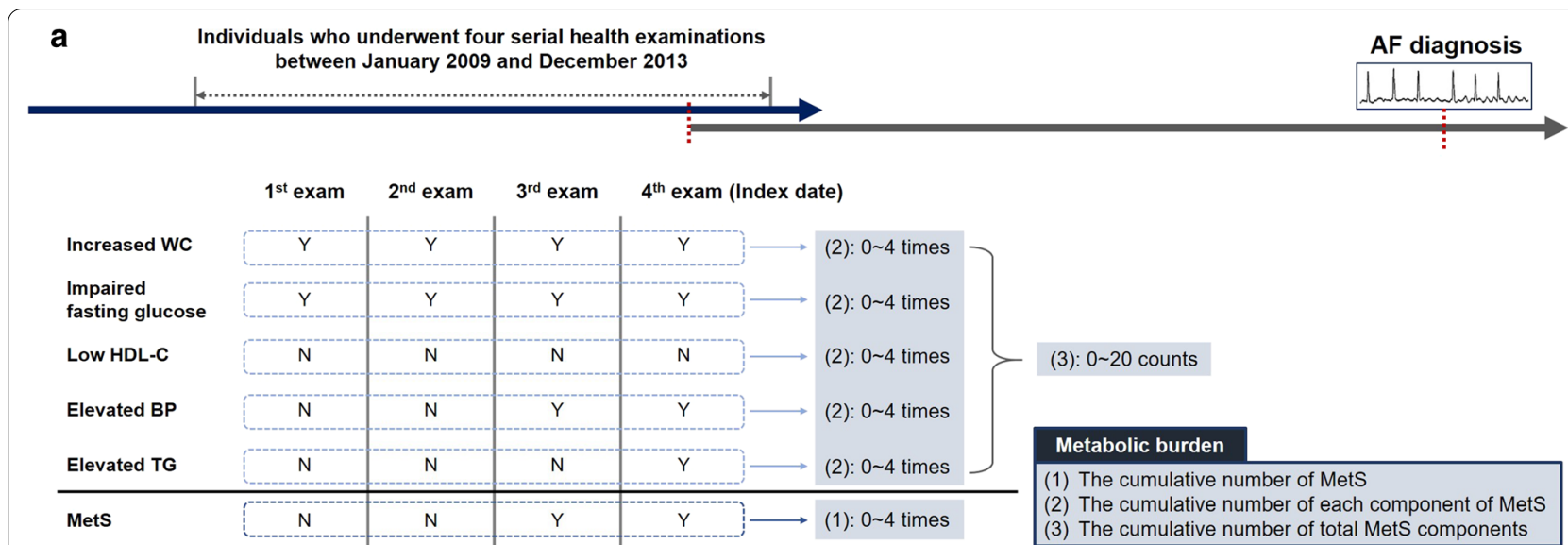

b

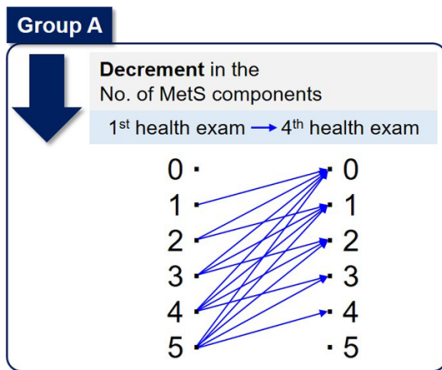

\section{Group B}
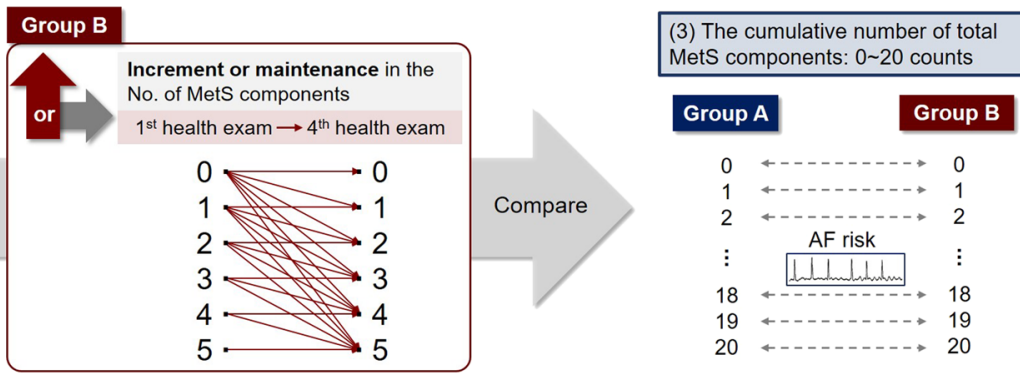

Fig. 1 a Overall scheme of study and three different ways of defining metabolic burdens. $\mathbf{b}$ Evaluation of temporal trends in the metabolic burden on the incidence of AF. AF atrial fibrillation, MetS metabolic syndrome, WC waist circumference, HDL-C high-density lipoprotein cholesterol, BP blood pressure, $T G$ triglycerides, $Y$ yes, $N$ no

of total MetS components, we matched two groups and compared the risk of AF (hazard ratio [HR] with 95\% confidence interval $[\mathrm{CI}]$ of group A was enumerated with reference to Group B).

\section{Covariates, follow-up, and clinical outcomes}

Baseline characteristics of the participants were designated as the data of the last health examination (index date), which includes sociodemographic data, incomebased insurance contributions, laboratory results, anthropometric measurements, comorbidities (diabetes mellitus, hypertension, dyslipidemia, peripheral artery disease, chronic obstructive pulmonary disease, myocardial infarction, heart failure, cancer, and chronic kidney disease) and answers to detailed lifestyle questionnaires. We investigated the risk of new-onset AF using the International Classification of Diseases, Tenth Revision (ICD-10), codes with inpatient and outpatient records. Detailed definitions of AF and comorbidities are summarized in Additional file 1: Table S1 [22]. The follow-up period was the time from the index date to the occurrence of AF or December 31, 2018, whichever came first.

\section{Statistical analysis}

Data are reported as means \pm standard deviations for continuous variables and number (\%) for categorical variables. To evaluate significant differences in baseline characteristics among groups categorized by the number of MetS components, one-way analysis of variance and chi-square test were used. The incidence rate of AF was computed by dividing new-onset AF cases by the total follow-up duration and presented as per 1000 person-years (PY). The association between the frequency of MetS status and the incidence of AF was estimated using Cox proportional hazards regression models. The risk of AF according to the number of MetS compared to the non-MetS group was expressed as HRs with 95\% CIs. Model 1 represents an unadjusted risk, and Model 2 was adjusted for age, sex, smoking status (never smoker, ex-smoker, or current smoker), alcohol intake (non, mild, or heavy drinker, g/day), regular exercise (performing $>30$ min of moderate physical activity $\geq 5$ times a week or $>20 \mathrm{~min}$ of vigorous physical activity $\geq 3$ times a week), and low-income level (income in lower $20 \%$ among the entire Korean population of subjects supported by the medical aid program) [25]. Model 3 was additionally adjusted for WC, systolic 
blood pressure, fasting glucose, logarithm of TG, and HDL-C levels.

To verify the robustness of our results, we performed several subgroups and sensitivity analyses with regard to the association between the cumulative number of total MetS components diagnosed at each health examination ( 0 to a maximum of 20) and the risk of AF. First, we investigated the association between the cumulative frequency of metabolic components and the risk of AF according to sex and the presence of obesity to determine potential effect modifications. We also conducted an analysis by excluding participants with AF diagnosed in the first 2 years of follow-up to minimize the effect of reverse causality. Data collection and statistical analyses were performed using SAS version 9.4 (SAS Institute, Cary, NC).

\section{Results}

The baseline characteristics of 2885189 participants grouped according to the number of MetS diagnosed over four health examinations are summarized in Table 1. The mean participant age was $44.5 \pm 10.9$ years, and 2 058645 (71.4\%) were men. Individuals were divided into five groups: 1800268 (62.4\%), 428143 (14.8\%), 250073 (8.7\%), 188847 (6.5\%), and 217858 (7.6\%) who met the diagnostic criteria of MetS 0, 1, 2, 3, and 4 times, respectively. Diabetes, hypertension, and dyslipidemia were present in $7.1 \%, 20.7 \%$, and $17.3 \%$ of the total population, respectively. The prevalence of comorbidities was higher as individuals fulfilled more MetS criteria.

\section{Accumulation of metabolic burden and the risk of AF}

The follow-up period was $5.3 \pm 0.3$ years. The incidence of AF, according to the number of MetS and the number of MetS components during the four health examinations are described in Table 2. The risk of AF showed a positive association with the cumulative number of MetS diagnosed at each health examination: adjusted HRs with 95\% CIs of groups meeting the diagnostic criteria of MetS 1, 2, 3, and 4 times compared to 0 time were 1.18 (1.13-1.24), 1.31 (1.25-1.39), 1.46 (1.38-1.55), and 1.72 $(1.63-1.82), P$ for trend $<0.001$. The association is illustrated in Fig. 2a.

All five MetS components were independently associated with the risk of AF. As the number of MetS components accumulated, the risk of AF also increased (Table 2 and Fig. 2b). The effect of each MetS component on the risk of AF was different. The adjusted HR (95\% CI) of each MetS component, when diagnosed four times consecutively, was as follows: $1.96(1.87-2.07)$ for elevated blood pressure, 1.44 (1.37-1.52) for low HDL-C, 1.35 (1.27-1.44) for increased WC, 1.27 (1.21-1.34) for elevated TG, and $1.22(1.15-1.29)$ for impaired fasting glucose.
Table 3 and Fig. 2c show the relationship between metabolic burden as the cumulative number of all MetS components during the four health examinations and the risk of AF. As participants had an accumulation of metabolic components from 0 to 20 counts, the risk of $\mathrm{AF}$ also gradually increased by approximately 3.1 -fold compared to those without any metabolic components (HR 3.11, 95\% CI 2.52-3.83 in those with 20 components of MetS). Kaplan-Meier estimates of the cumulative incidence probability of AF are shown in Fig. 3.

\section{Temporal trends of metabolic burden and the risk of AF}

We compared the risk of AF according to the temporal trends in metabolic burden (Fig. 4 and Additional file 1: Table S2). From 3 to 12 counts of the total cumulative metabolic components during the four health examinations, group A (with a decrease in the number of MetS components) exhibited a lower risk of AF than group B (with an increase or maintenance in the number of MetS components). Those with less than 3 or more than 12 MetS components presented insignificant differences in the risk of AF regarding the temporal change in metabolic burden.

\section{Subgroup and sensitivity analysis}

Results of subgroup analyses of the association between $\mathrm{AF}$ risk and the cumulative number of MetS components, according to sex and obesity, are shown in Additional file 1: Table S3 and Table S4, respectively. The incidence of AF did not show an interaction with sex or the presence of obesity ( $P$-for-interaction 0.25 and 0.77 , respectively).

In sensitivity analysis excluding participants with AF diagnosed in the first 2 years of follow-up, the progressive increase in the risk of AF according to the cumulative number of all MetS components was consistent with the main results (Additional file 1: Table S5).

\section{Discussion}

To the best of our knowledge, this is the first study to report the cumulative burden of MetS and its components on the risk of AF in a large nationwide populationbased cohort study. We demonstrated several principal findings, which are summarized as follows: (1) the cumulative burden of MetS during the four health examinations had a linear correlation with the risk of AF; (2) the cumulative burden of each MetS component showed a positive association with the risk of AF; (3) among the five metabolic components, elevated blood pressure had the greatest increase in AF risk; (4) the cumulative number of total MetS components showed an incremental association with the risk of AF; and (5) temporal trends in MetS burden had a different effect on the risk of AF. 
Table 1 Baseline characteristics of the total study population according to the cumulative number of MetS diagnosed at each health examination ( 0 to 4 times)

\begin{tabular}{|c|c|c|c|c|c|c|c|}
\hline & \multirow[t]{2}{*}{ Total } & \multicolumn{5}{|c|}{ The number of the presence of metabolic syndrome } & \multirow[t]{2}{*}{$\mathrm{p}$} \\
\hline & & 0 & 1 & 2 & 3 & 4 & \\
\hline No. of participants (\%) & $2,885,189(100.0)$ & $1,800,268(62.4)$ & $428,143(14.8)$ & $250,073(8.7)$ & $188,847(6.5)$ & $217,858(7.6)$ & \\
\hline Age (years) & $44.54 \pm 10.85$ & $42.38 \pm 10.39$ & $46.30 \pm 10.58$ & $47.93 \pm 10.66$ & $49.11 \pm 10.49$ & $51.07 \pm 10.16$ & $<0.001$ \\
\hline \multicolumn{8}{|l|}{ Sex } \\
\hline Male & $2,058,645(71.4)$ & $1,197,934(66.5)$ & $337,756(78.9)$ & $200,399(80.1)$ & $152,483(80.7)$ & $170,073(78.1)$ & $<0.001$ \\
\hline Female & $826,544(28.7)$ & $602,334(33.5)$ & $90,387(21.1)$ & $49,674(19.9)$ & $36,364(19.3)$ & $47,785(21.9)$ & \\
\hline Smoking & & & & & & & $<0.001$ \\
\hline Never smoker & $1,369,623(47.5)$ & $938,078(52.1)$ & $174,286(40.7)$ & $97,977(39.2)$ & $72,215(38.2)$ & $87,067(40.0)$ & \\
\hline Ex-smoker & $601,896(20.9)$ & $336,101(18.7)$ & $100,158(23.4)$ & $61,532(24.6)$ & $48,473(25.7)$ & $55,632(25.5)$ & \\
\hline Current smoker & $913,670(31.7)$ & $526,089(29.2)$ & $153,699(35.9)$ & $90,564(36.2)$ & $68,159(36.1)$ & $75,159(34.5)$ & \\
\hline Alcohol consumption ${ }^{\mathrm{a}}$ & & & & & & & $<0.001$ \\
\hline Non-drinker & $1,131,332(39.2)$ & $728,676(40.5)$ & $156,540(36.6)$ & $91,741(36.7)$ & $69,234(36.7)$ & $85,141(39.1)$ & \\
\hline Mild to moderate drinker & $1,511,675(52.4)$ & $947,766(52.7)$ & $228,079(53.3)$ & $130,842(52.3)$ & $97,706(51.7)$ & $107,282(49.2)$ & \\
\hline Heavy drinker & $242,182(8.4)$ & $123,826(6.9)$ & $43,524(10.2)$ & $27,490(11.0)$ & $21,907(11.6)$ & $25,435(11.7)$ & \\
\hline Regular exercise ${ }^{b}$ & $642,402(22.3)$ & $390,171(21.7)$ & $98,815(23.1)$ & $57,963(23.2)$ & $43,981(23.3)$ & $51,472(23.6)$ & $<0.001$ \\
\hline Low income ${ }^{c}$ & $579,366(20.1)$ & $329,917(18.3)$ & $89,519(20.9)$ & $55,953(22.4)$ & $43,219(22.9)$ & $60,758(27.9)$ & $<0.001$ \\
\hline \multicolumn{8}{|l|}{ Comorbidities } \\
\hline Diabetes mellitus & $204,495(7.1)$ & $35,151(2.0)$ & $28,569(6.7)$ & $28,964(11.6)$ & $35,968(19.1)$ & $75,843(34.8)$ & $<0.001$ \\
\hline Hypertension & $597,210(20.7)$ & $173,667(9.7)$ & $106,689(24.9)$ & $89,778(35.9)$ & $88,335(46.8)$ & $138,741(63.7)$ & $<0.001$ \\
\hline Dyslipidemia & $499,947(17.3)$ & $177,145(9.8)$ & $87,677(20.5)$ & $68,089(27.2)$ & $64,119(34.0)$ & $102,917(47.2)$ & $<0.001$ \\
\hline PAD & $198,421(6.9)$ & $76,179(4.2)$ & $32,740(7.7)$ & $25,468(10.2)$ & $24,067(12.7)$ & $39,967(18.3)$ & $<0.001$ \\
\hline COPD & $590,393(20.5)$ & $344,502(19.1)$ & $89,663(20.9)$ & $56,012(22.4)$ & $44,029(23.3)$ & $56,187(25.8)$ & $<0.001$ \\
\hline Ml & $37,979(1.3)$ & $15,751(0.9)$ & $6212(1.5)$ & $4545(1.8)$ & $4269(2.3)$ & $7202(3.3)$ & $<0.001$ \\
\hline $\mathrm{HF}$ & $32,611(1.13)$ & $12,590(0.7)$ & $5126(1.2)$ & $4122(1.65)$ & $3952(2.09)$ & $6821(3.13)$ & $<0.001$ \\
\hline Cancer & $42,378(1.5)$ & $24,148(1.3)$ & $6579(1.5)$ & $4077(1.6)$ & $3364(1.8)$ & $4210(1.9)$ & $<0.001$ \\
\hline CKD & $56,830(2.0)$ & $23,580(1.3)$ & $8867(2.1)$ & $7108(2.8)$ & $6702(3.6)$ & $10,573(4.9)$ & $<0.001$ \\
\hline \multicolumn{8}{|l|}{ Laboratory findings } \\
\hline BMI $\left(\mathrm{kg} / \mathrm{m}^{2}\right)$ & $23.84 \pm 3.16$ & $22.72 \pm 2.66$ & $24.80 \pm 2.75$ & $25.68 \pm 2.88$ & $26.34 \pm 3.00$ & $26.91 \pm 3.22$ & $<0.001$ \\
\hline Waist circumference $(\mathrm{cm})$ & $80.79 \pm 8.85$ & $77.55 \pm 7.76$ & $83.72 \pm 7.25$ & $86.15 \pm 7.40$ & $87.96 \pm 7.58$ & $89.50 \pm 8.17$ & $<0.001$ \\
\hline Systolic BP (mmHg) & $121.68 \pm 13.55$ & $118.11 \pm 12.45$ & $125.18 \pm 12.66$ & $127.71 \pm 12.91$ & $129.38 \pm 13.17$ & $130.65 \pm 13.81$ & $<0.001$ \\
\hline Diastolic BP (mmHg) & $76.59 \pm 9.48$ & $74.39 \pm 8.84$ & $78.80 \pm 8.97$ & $80.37 \pm 9.19$ & $81.39 \pm 9.44$ & $81.94 \pm 9.85$ & $<0.001$ \\
\hline Fasting glucose (mg/dL) & $96.7 \pm 20.65$ & $91.64 \pm 13.28$ & $98.76 \pm 19.15$ & $103.09 \pm 23.41$ & $108.24 \pm 28.56$ & $117.16 \pm 36.52$ & $<0.001$ \\
\hline Total cholesterol (mg/dL) & $195.09 \pm 35.07$ & $191.10 \pm 32.91$ & $200.74 \pm 35.66$ & $203.00 \pm 37.03$ & $203.23 \pm 38.35$ & $200.80 \pm 40.45$ & $<0.001$ \\
\hline HDL cholesterol (mg/dL) & $54.78 \pm 14.83$ & $58.13 \pm 14.4$ & $51.13 \pm 13.84$ & $49.00 \pm 13.74$ & $47.55 \pm 13.41$ & $47.08 \pm 13.73$ & $<0.001$ \\
\hline LDL cholesterol (mg/dL) & $113.98 \pm 32.14$ & $111.91 \pm 30.09$ & $118.58 \pm 33.16$ & $118.82 \pm 34.72$ & $117.50 \pm 35.94$ & $113.46 \pm 37.65$ & $<0.001$ \\
\hline eGFR (ml/min/1.73m2) & $92.75 \pm 37.86$ & $94.19 \pm 38.14$ & $91.57 \pm 37.51$ & $90.37 \pm 37.02$ & $89.73 \pm 38.14$ & $88.56 \pm 36.24$ & $<0.001$ \\
\hline Triglyceride (mg/dL) & $135.98 \pm 92.48$ & $106.77 \pm 64.50$ & $160.86 \pm 94.11$ & $184.62 \pm 106.67$ & $201.99 \pm 114.90$ & $215.47 \pm 126.08$ & $<0.001$ \\
\hline \multicolumn{8}{|l|}{ Medication } \\
\hline Statin & $245,676(8.5)$ & $56,971(3.2)$ & $39,209(9.2)$ & $36,314(14.5)$ & $38,637(20.5)$ & $74,545(34.2)$ & $<0.001$ \\
\hline
\end{tabular}

Data are presented as means \pm SD or No. (Percentages)

Percentages may not total 100 because of rounding

MetS metabolic syndrome, $P A D$ peripheral artery disease, COPD chronic obstructive pulmonary disease, $M I$ myocardial infarction, $H F$ heart failure, $C K D$ chronic kidney disease, $B M I$ body mass index, $B P$ blood pressure, $H D L$ high-density lipoprotein, $L D L$ low-density lipoprotein, eGFR estimated glomerular filtration rate

${ }^{a}$ Alcohol consumption denotes as following

Non-drinker: alcohol consumption $0 \mathrm{~g}$

Mild to moderate drinker: alcohol consumption $>0 \mathrm{~g}$ to $<30 \mathrm{~g}$ per day

Heavy drinker: alcohol consumption $\geq 30 \mathrm{~g}$ per day

${ }^{\mathrm{b}}$ Regular exercise denotes performing $>30$ min of moderate-intensity exercise (e.g. brisk pace walking, tennis doubles, or bicycling leisurely) $\geq 5$ times a week or $>20$ min of vigorous-intensity exercise (e.g. running, climbing, fast cycling, or aerobics) $\geq 3$ times a week

c Low income denotes income belongs to lower $20 \%$ among entire Korean population of subjects supported by the Medical Aid program 
Table 2 The risk of atrial fibrillation according to the cumulative number of MetS and each component diagnosed during four health examinations ( 0 to 4 times)

\begin{tabular}{|c|c|c|c|c|c|c|}
\hline \multirow{2}{*}{$\begin{array}{l}\text { The number of meeting } \\
\text { the component }\end{array}$} & \multirow[t]{2}{*}{ No. of participants } & \multirow[t]{2}{*}{$\mathrm{AF}$} & \multirow[t]{2}{*}{ IR (1000PY) } & \multicolumn{3}{|l|}{$\mathrm{HR}(95 \% \mathrm{Cl})$} \\
\hline & & & & Model 1 & Model 2 & Model 3 \\
\hline \multicolumn{7}{|l|}{ Metabolic syndrome } \\
\hline 0 & $1,800,268$ & 7584 & 0.80 & 1.00 (Reference) & 1.00 (Reference) & 1.00 (Reference) \\
\hline 1 & 428,143 & 3025 & 1.35 & $1.69(1.62-1.77)$ & $1.21(1.16-1.27)$ & $1.18(1.13-1.24)$ \\
\hline 2 & 250,073 & 2248 & 1.72 & $2.16(2.06-2.27)$ & $1.37(1.31-1.44)$ & $1.31(1.25-1.39)$ \\
\hline 3 & 188,847 & 2071 & 2.10 & $2.64(2.52-2.77)$ & $1.55(1.48-1.63)$ & $1.46(1.38-1.55)$ \\
\hline \multirow[t]{2}{*}{4} & 217,858 & 3184 & 2.81 & $3.54(3.39-3.69)$ & $1.87(1.80-1.95)$ & $1.72(1.63-1.82)$ \\
\hline & & & & $p<0.001$ & $p<0.001$ & $p<0.001$ \\
\hline \multicolumn{7}{|c|}{ Increased waist circumference } \\
\hline 0 & $2,063,537$ & 10,304 & 0.95 & 1.00 (Reference) & 1.00 (Reference) & 1.00 (Reference) \\
\hline 1 & 298,977 & 2292 & 1.47 & $1.55(1.48-1.63)$ & $1.24(1.19-1.30)$ & $1.12(1.06-1.17)$ \\
\hline 2 & 171,305 & 1487 & 1.66 & $1.76(1.67-1.86)$ & $1.31(1.24-1.39)$ & $1.13(1.06-1.20)$ \\
\hline 3 & 147,806 & 1570 & 2.04 & $2.16(2.05-2.28)$ & $1.56(1.48-1.64)$ & $1.29(1.21-1.37)$ \\
\hline \multirow[t]{2}{*}{4} & 203,564 & 2459 & 2.32 & $2.46(2.35-2.57)$ & $1.76(1.69-1.84)$ & $1.35(1.27-1.44)$ \\
\hline & & & & $p<0.001$ & $p<0.001$ & $p<0.001$ \\
\hline \multicolumn{7}{|l|}{ Impaired fasting glucose } \\
\hline 0 & $1,290,283$ & 5344 & 0.78 & 1.00 (Reference) & 1.00 (Reference) & 1.00 (Reference) \\
\hline 1 & 682,047 & 3952 & 1.10 & $1.41(1.35-1.47)$ & $1.11(1.06-1.16)$ & $1.08(1.03-1.12)$ \\
\hline 2 & 385,692 & 2949 & 1.46 & $1.87(1.79-1.95)$ & $1.22(1.17-1.28)$ & $1.16(1.10-1.21)$ \\
\hline 3 & 244,101 & 2323 & 1.82 & $2.33(2.22-2.45)$ & $1.30(1.23-1.36)$ & $1.19(1.13-1.26)$ \\
\hline \multirow[t]{2}{*}{4} & 283,066 & 3544 & 2.41 & $3.08(2.96-3.22)$ & $1.39(1.33-1.45)$ & $1.22(1.15-1.29)$ \\
\hline & & & & $p<0.001$ & $p<0.001$ & $p<0.001$ \\
\hline \multicolumn{7}{|l|}{ Low HDL-C } \\
\hline 0 & $1,817,377$ & 9598 & 1.00 & 1.00 (Reference) & 1.00 (Reference) & 1.00 (Reference) \\
\hline 1 & 439,918 & 2973 & 1.29 & $1.29(1.24-1.34)$ & $1.17(1.12-1.22)$ & $1.15(1.10-1.20)$ \\
\hline 2 & 242,845 & 1817 & 1.43 & $1.43(1.36-1.50)$ & $1.23(1.17-1.29)$ & $1.19(1.13-1.26)$ \\
\hline 3 & 182,602 & 1585 & 1.65 & $1.65(1.56-1.74)$ & $1.40(1.32-1.47)$ & $1.35(1.28-1.43)$ \\
\hline \multirow[t]{2}{*}{4} & 202,447 & 2139 & 2.02 & $2.02(1.92-2.11)$ & $1.52(1.45-1.59)$ & $1.44(1.37-1.52)$ \\
\hline & & & & $p<0.001$ & $p<0.001$ & $p<0.001$ \\
\hline \multicolumn{7}{|l|}{ Elevated blood pressure } \\
\hline 0 & 994,829 & 3048 & 0.58 & 1.00 (Reference) & 1.00 (Reference) & 1.00 (Reference) \\
\hline 1 & 568,202 & 2461 & 0.82 & $1.42(1.34-1.49)$ & $1.12(1.07-1.19)$ & $1.13(1.07-1.19)$ \\
\hline 2 & 417,544 & 2492 & 1.14 & $1.96(1.86-2.07)$ & $1.33(1.26-1.41)$ & $1.35(1.28-1.43)$ \\
\hline 3 & 343,192 & 2510 & 1.40 & $2.41(2.29-2.54)$ & $1.41(1.34-1.49)$ & $1.44(1.36-1.53)$ \\
\hline \multirow[t]{2}{*}{4} & 561,422 & 7601 & 2.59 & $4.48(4.29-4.67)$ & $1.97(1.88-2.05)$ & $1.96(1.87-2.07)$ \\
\hline & & & & $p<0.001$ & $p<0.001$ & $p<0.001$ \\
\hline \multicolumn{7}{|l|}{ Elevated TG } \\
\hline 0 & $1,284,347$ & 6255 & 0.92 & 1.00 (Reference) & 1.00 (Reference) & 1.00 (Reference) \\
\hline 1 & 506,800 & 3189 & 1.20 & $1.30(1.24-1.35)$ & $1.07(1.02-1.11)$ & $1.06(1.01-1.11)$ \\
\hline 2 & 352,286 & 2415 & 1.31 & $1.42(1.35-1.48)$ & $1.06(1.01-1.12)$ & $1.05(1.00-1.11)$ \\
\hline 3 & 316,707 & 2435 & 1.46 & $1.59(1.51-1.66)$ & $1.15(1.09-1.20)$ & $1.13(1.08-1.20)$ \\
\hline \multirow[t]{2}{*}{4} & 425,049 & 3818 & 1.71 & $1.86(1.79-1.94)$ & $1.29(1.24-1.34)$ & $1.27(1.21-1.34)$ \\
\hline & & & & $p<0.001$ & $p<0.001$ & $p<0.001$ \\
\hline
\end{tabular}

Model 1 is unadjusted

Model 2 is adjusted for age, sex, smoking status, alcohol intake, regular exercise, and low income

Model 3 is adjusted for age, sex, smoking status, alcohol intake, regular exercise, low income, waist circumference, systolic blood pressure, fasting glucose, logarithm of TG, and HDL-C level

$A F$ atrial fibrillation, $I R$ incidence rate, $P Y$ person-years, $H R$ hazard ratio, $C l$ confidence interval, $H D L-C$ high-density lipoprotein cholesterol, $T G$ triglycerides 


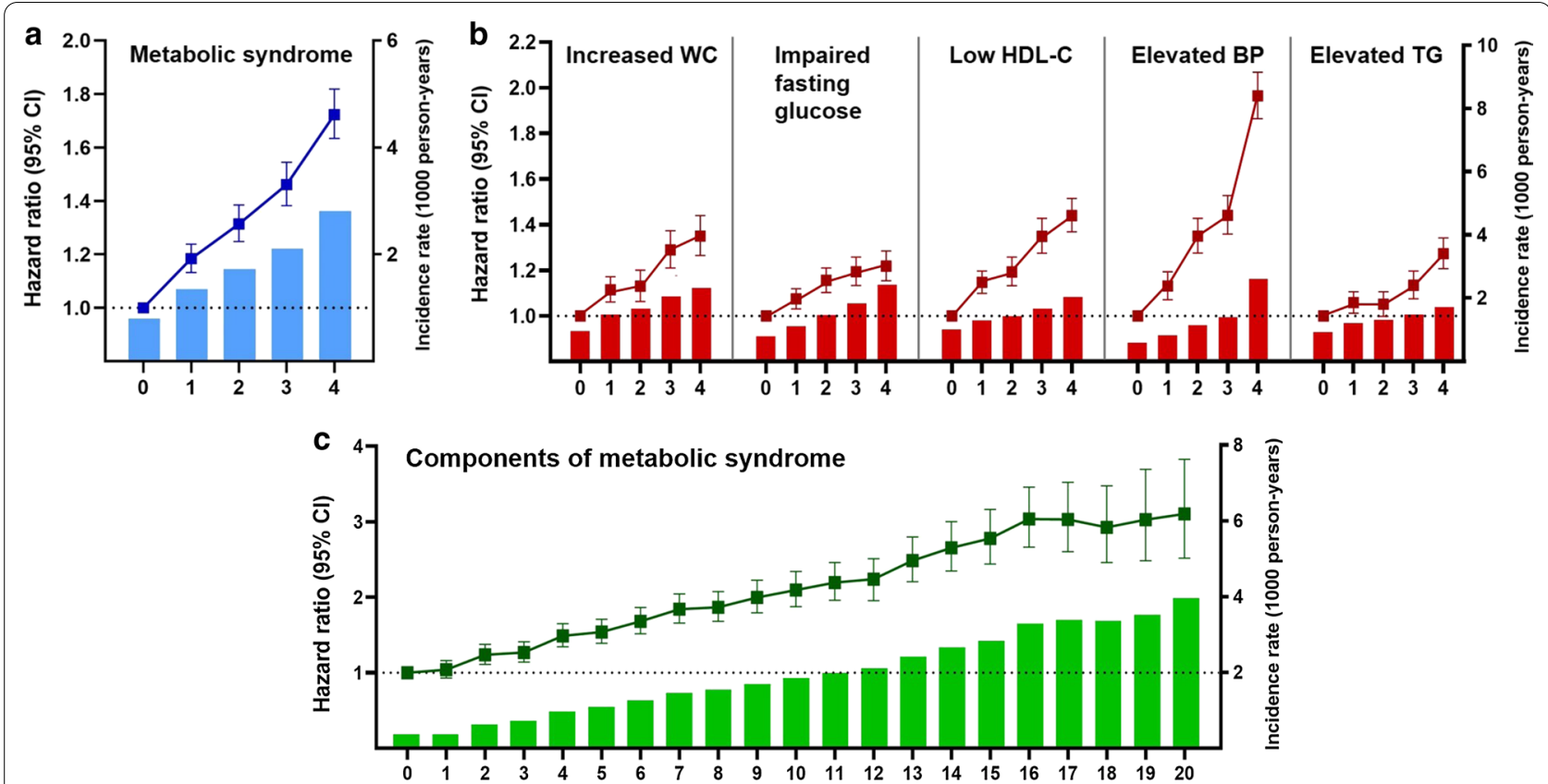

Fig. 2 Incidence of atrial fibrillation according to the a cumulative number of MetS diagnosed at each health examination, $\mathbf{b}$ cumulative number of each component of MetS diagnosed at each health examination, and $\mathbf{c}$ cumulative number of total MetS components diagnosed during four health examinations. WC waist circumference, HDL-C high-density lipoprotein cholesterol, TG triglycerides

Both MetS and AF confer a high burden of cardiovascular morbidity and mortality, and the association between MetS and AF has been reported in various studies $[10,11,26,27]$. Compelling evidence supports that MetS itself is associated with the development of AF, and the presence of an increasing number of MetS components predisposes individuals to a higher risk of AF [11, 26, 28-30]. However, these studies analyzed the number of MetS components at a single point. In contrast to previous studies, we have investigated the influence of temporal accumulation of MetS by combining four serial health examinations collectively. While participants diagnosed with MetS once had an 18\% increased risk of AF compared to that in non-MetS participants, those diagnosed with MetS repeatedly at four times of measurement had a $72 \%$ higher risk of AF. Notably, the risk of AF increased by 3.1-fold as the number of fulfilled MetS components increased to a total of 20 counts during consecutive health examinations. Such a positive increase in AF according to a repetitive diagnosis of metabolic components might suggest a dose-response (or temporal accumulation) perspective in evaluating the hazards of cardiovascular diseases. This finding is noticeable because it implicates that the risk of AF development is different among patients with metabolic derangements depending on the past and upcoming metabolic burden. Given the proportional increase in AF risk according to the degree of metabolic burden integrating temporal changes, it is plausible to infer that the risk of AF would be higher in those diagnosed with MetS more than four times during their health examination checkups.

Regarding the relationship between elevated TG and the risk of $\mathrm{AF}$, there were controversial reports $[11,26$, 28, 31, 32]. The Niigata Preventive Medicine Study and post-hoc analysis from the ARIC study reported that hypertriglyceridemia was not related to incident AF [11, 26]. In addition, a recent study reported no association between elevated TG levels and the risk of AF [32]. However, the Multi-Ethnic Study of Atherosclerosis (MESA) and the Framingham Heart Study (FHS) reported that hypertriglyceridemia was associated with a higher risk of AF [31]. In our study, meeting the criteria of elevated TG once or twice during 4 times of health screening examinations seems insignificantly or minimally associated with the risk of AF. Nonetheless, the association became evident as elevated TG levels were repeatedly checked, whereby the risk of AF was as high as $27 \%$ if hypertriglyceridemia was repeatedly confirmed through the entire health examinations of the study period, even after adjusting for potential confounders and other MetS components. Elevated TG is reported to be associated with endothelial dysfunction and the presence of microvascular disease [33,34], which could be an early manifestation of atherosclerosis. Moreover, it is related to an increased risk of recurrent coronary artery disease [35], as well as insulin resistance, and is known to increase blood glucose 
Table 3 The risk of atrial fibrillation according to the cumulative number of total MetS components diagnosed during four health examinations ( 0 to 20 times)

\begin{tabular}{|c|c|c|c|c|c|c|}
\hline \multirow{2}{*}{$\begin{array}{l}\text { The number of meeting } \\
\text { individual components }\end{array}$} & \multirow[t]{2}{*}{ No. of participants } & \multirow[t]{2}{*}{$\mathrm{AF}$} & \multirow[t]{2}{*}{ IR (1000PY) } & \multicolumn{3}{|l|}{$\mathrm{HR}(95 \% \mathrm{CI})$} \\
\hline & & & & Model1 & Model2 & Model3 \\
\hline 0 & 278,704 & 549 & 0.37 & 1.00 (Reference) & 1.00 (Reference) & 1.00 (Reference) \\
\hline 1 & 297,650 & 729 & 0.37 & $1.25(1.12-1.39)$ & $1.03(0.92-1.15)$ & $1.04(0.93-1.16)$ \\
\hline 2 & 283,079 & 939 & 0.63 & $1.69(1.52-1.88)$ & $1.21(1.09-1.34)$ & $1.24(1.11-1.38)$ \\
\hline 3 & 265,009 & 1007 & 0.72 & $1.94(1.75-2.15)$ & $1.23(1.11-1.36)$ & $1.27(1.14-1.41)$ \\
\hline 4 & 263,875 & 1345 & 0.97 & $2.61(2.36-2.88)$ & $1.43(1.30-1.58)$ & $1.49(1.35-1.65)$ \\
\hline 5 & 235,071 & 1342 & 1.08 & $2.92(2.65-3.23)$ & $1.47(1.33-1.62)$ & $1.54(1.39-1.71)$ \\
\hline 6 & 210,455 & 1397 & 1.26 & $3.41(3.09-3.76)$ & $1.59(1.44-1.75)$ & $1.68(1.52-1.87)$ \\
\hline 7 & 187,332 & 1427 & 1.45 & $3.92(3.55-4.32)$ & $1.72(1.56-1.90)$ & $1.84(1.66-2.04)$ \\
\hline 8 & 173,024 & 1407 & 1.55 & $4.18(3.79-4.62)$ & $1.74(1.58-1.93)$ & $1.87(1.68-2.08)$ \\
\hline 9 & 144,294 & 1282 & 1.70 & $4.58(4.15-5.06)$ & $1.85(1.67-2.05)$ & $2.00(1.79-2.23)$ \\
\hline 10 & 122,156 & 1179 & 1.85 & $4.99(4.50-5.52)$ & $1.94(1.75-2.15)$ & $2.10(1.88-2.34)$ \\
\hline 11 & 100,785 & 1046 & 1.99 & $5.37(4.84-5.96)$ & $2.03(1.82-2.25)$ & $2.20(1.96-2.46)$ \\
\hline 12 & 89,005 & 980 & 2.11 & $5.70(5.13-6.33)$ & $2.07(1.86-2.30)$ & $2.24(2.00-2.51)$ \\
\hline 13 & 68,103 & 855 & 2.41 & $6.51(5.85-7.25)$ & $2.29(2.06-2.56)$ & $2.49(2.21-2.80)$ \\
\hline 14 & 52,236 & 723 & 2.66 & $7.19(6.43-8.03)$ & $2.46(2.19-2.75)$ & $2.66(2.35-3.00)$ \\
\hline 15 & 38,764 & 572 & 2.84 & $7.67(6.82-8.62)$ & $2.57(2.29-2.90)$ & $2.78(2.44-3.16)$ \\
\hline 16 & 32,590 & 556 & 3.29 & 8.88 (7.89-9.99) & $2.81(2.50-3.17)$ & $3.04(2.66-3.46)$ \\
\hline 17 & 17,981 & 316 & 3.39 & $9.16(7.98-10.52)$ & $2.87(2.50-3.30)$ & $3.03(2.61-3.52)$ \\
\hline 18 & 11,711 & 204 & 3.36 & $9.07(7.73-10.66)$ & $2.81(2.39-3.30)$ & $2.93(2.46-3.48)$ \\
\hline 19 & 7451 & 136 & 3.52 & $9.50(7.87-11.46)$ & $2.94(2.43-3.55)$ & $3.03(2.48-3.69)$ \\
\hline \multirow[t]{2}{*}{20} & 5914 & 121 & 3.97 & $10.73(8.81-13.06)$ & $3.15(2.58-3.84)$ & $3.11(2.52-3.83)$ \\
\hline & & & & $p<0.001$ & $p<0.001$ & $p<0.001$ \\
\hline
\end{tabular}

Model 1 is unadjusted

Model 2 is adjusted for age, sex, smoking status, alcohol intake, regular exercise, and low income

Model 3 is adjusted for age, sex, smoking status, alcohol intake, regular exercise, low income, waist circumference, systolic blood pressure, fasting glucose, logarithm of TG, and HDL-C level

$A F$ atrial fibrillation, $I R$ incidence rate, $P Y$ person-years, $H R$ hazard ratio, $C l$ confidence interval

levels [36]. Although the exact mechanism of the development of AF is not known, the pro-atherogenic property of elevated TG might play a role in AF development.

Along with hypertriglyceridemia, other metabolic components and MetS itself could be linked to a higher risk of AF by several pathophysiological mechanisms. Mechanical alterations including an increase in atrial size and ventricular hypertrophy due to MetS, obesity, hypertension, and low HDL-C may contribute to the development of AF [14, 37-40]. Atrial interstitial fibrosis, abnormal calcium homeostasis, and inappropriate neurohumoral activation led by insulin resistance are also reported to increased AF susceptibility [41]. Moreover, elevated levels of inflammation and oxidative stress have been proposed in the pathogenesis of both MetS and AF; indeed, HDL-C exerts anti-inflammatory and anti-oxidative activities that promote vascular health; hence, low HDL-C levels are related to a proinflammatory milieu [42-44]. These metabolic changes may predispose patients with MetS or individual metabolic components to AF development.
Meanwhile, elevated BP and low HDL-C levels have the most prominent increase in AF risk, which is consistent with prior research [11, 27]. Impaired fasting glucose showed only a modest increase in AF development, consistent with a recent study evaluating the impact of 'exposure' to metabolic syndrome on the increased risk of MI and stroke, both sharing common predisposing factors with AF [21]. Although the exact underlying mechanisms explaining the differences in magnitudes of AF risk among metabolic components are not answered in the present study, we could hypothesize that elevated BP and adverse lipid profiles play more pivotal roles on substrate formation for AF development. Also, as the prominent increase in the risk of AF according to repeated checks of impaired fasting glucose was attenuated after adjusting for other covariates, it might still contribute to the development of AF as a cluster of metabolic diseases rather than carry a sole dominant effect.

The International Diabetes Federation (IDF) estimates that approximately $25 \%$ of the world's population, which 

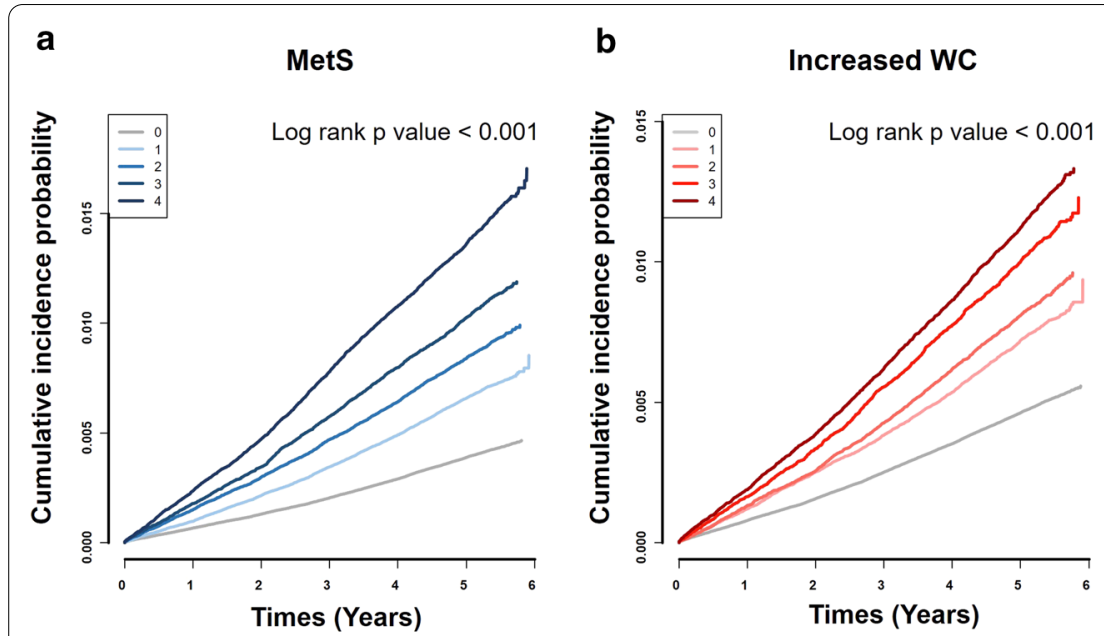

\section{C}

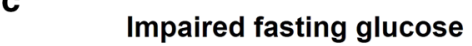

d

Low HDL-C

e
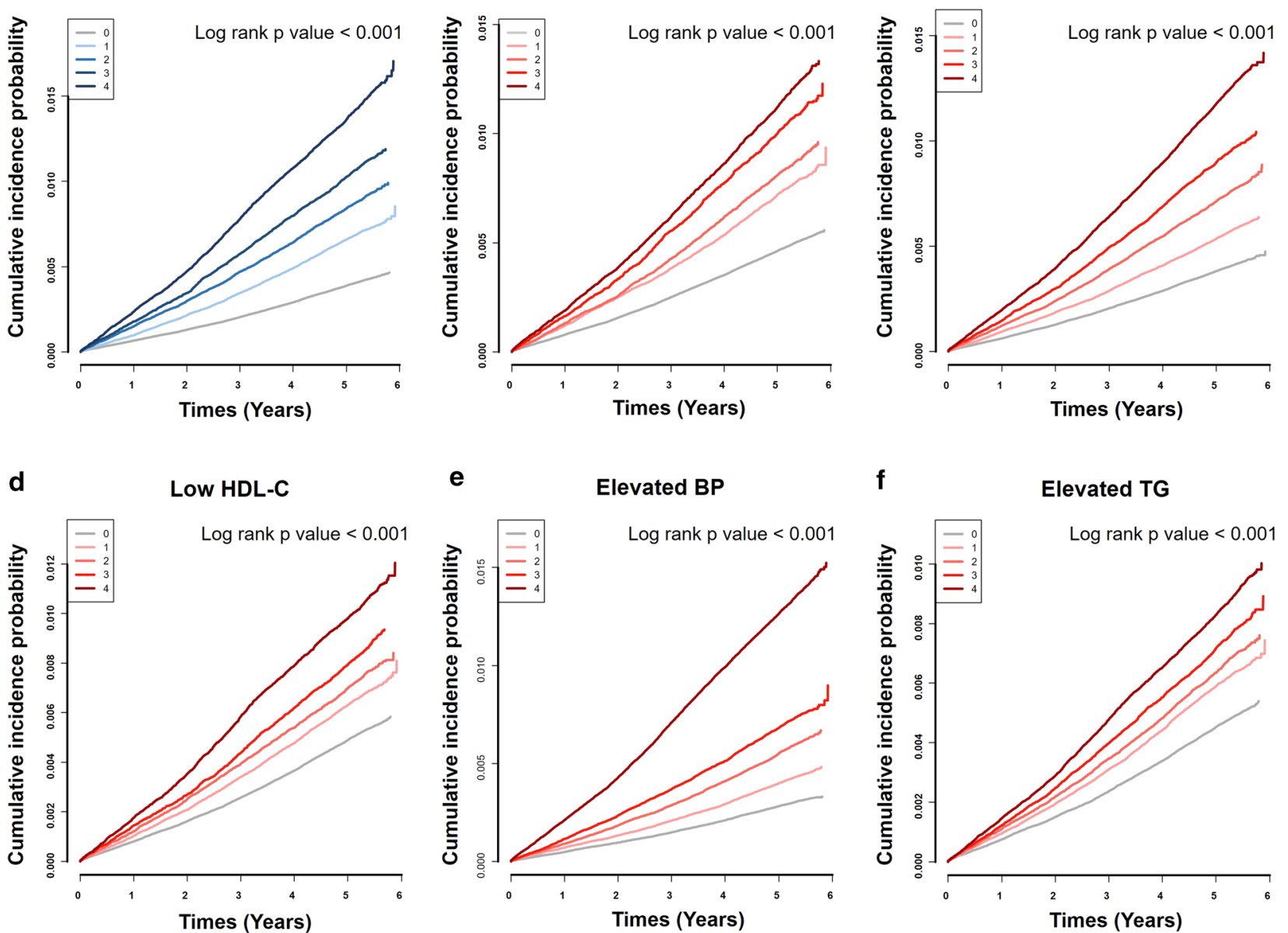

\section{Elevated BP}

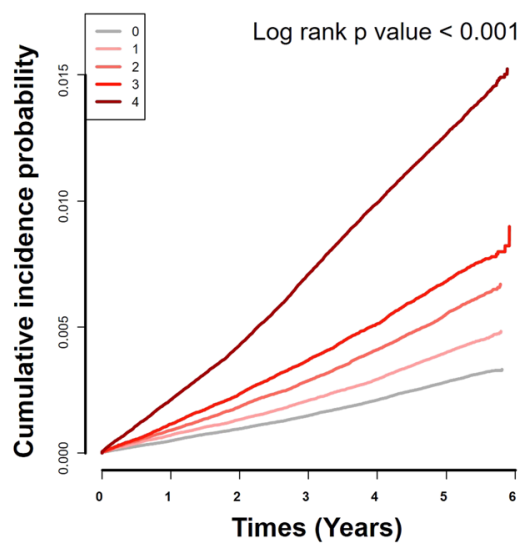

f

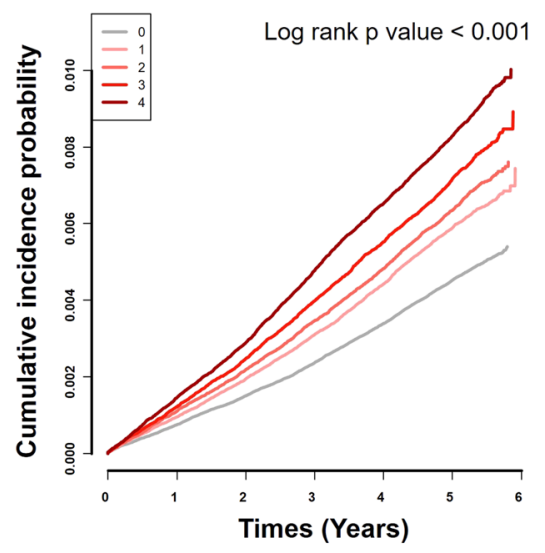

Fig. 3 Kaplan-Meier estimates of cumulative incidence probability of AF according to the cumulative number of a MetS, $\mathbf{b}$ increased waist circumference, $\mathbf{c}$ impaired fasting glucose, $\mathbf{d}$ low $\mathrm{HDL}-\mathrm{C}$, e elevated blood pressure, and $\mathbf{f}$ elevated TG during four health examinations. AF atrial fibrillation, MetS metabolic syndrome, WC waist circumference, $H D L-C$ high-density lipoprotein cholesterol, BP blood pressure, $T G$ triglycerides

corresponds to over a billion people, is affected by MetS despite the fact that the prevalence varies widely according to age, ethnicity, and sex of the population studied $[45,46]$. Considering that AF is strongly associated with cardiovascular diseases such as stroke, heart failure, myocardial infarction, dementia, and increased mortality [3, 47], exploring the pragmatic association between metabolic derangements and AF along with the understanding of potential subsequent diseases is important to address the public health care burden of AF and AF-related complications. Our large study population with a mean age at mid-forties, much younger than that reported in previous studies [11, 26, 27], thereby representing the most active group socioeconomically, contributes to emphasize the awareness of the group harboring the risk of AF and the early initiation of prevention strategies. Importantly, we ascertained that even meeting one or two components of MetS over time is sufficient to increase the risk of AF, and thus, it would be crucial to make a concerted effort to minimize the metabolic derangements.

Even within the participants who presented the same cumulative number of total MetS components in the four health examinations, each may carry a different risk of AF depending on the change in metabolic burden. Those with a decreased number of MetS components over time showed a lower risk of AF than participants with an increase or maintenance in the number of MetS components at the last health examination compared to the first examination. Given that recovery from MetS is known to be significantly associated with a decreased risk of major adverse cardiovascular events [48], our results are consistent with previous findings by focusing on the 


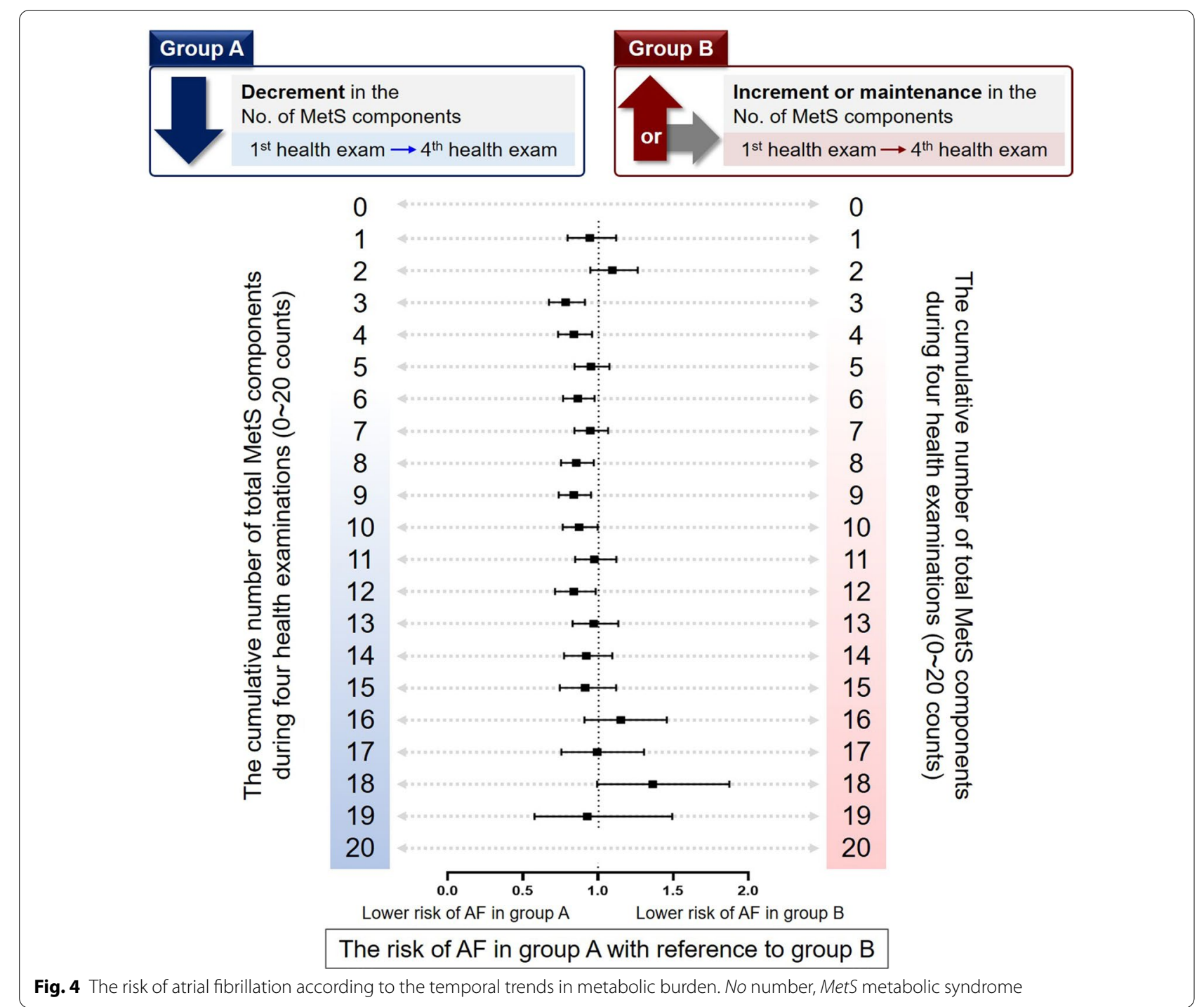

most common cardiac rhythm disorder, AF. Therefore, it would be important to manage MetS component(s) to mitigate the risk of AF, and this management should be considered as part of the overall management strategy for preventing AF $[49,50]$. Indeed, lifestyle modification (including addressing many risk factors within the MetS components) is part of the atrial fibrillation better care $(\mathrm{ABC})$ pathway for holistic AF care, which is advocated in the new 2020 ESC guidelines [51].

\section{Limitations}

Our study has several limitations. First, a considerable proportion of the study population already had diabetes mellitus and hypertension, which are evident and strong risk factors for AF. Instead, we show the risk gradient of AF by investigating the cumulative burden of metabolic derangements in a large general population at a relatively young age. Second, more than two-thirds of the study participants were men because employees are more likely to undergo regular health examinations provided at work places; hence, selection bias of sex might be introduced. However, subgroup analysis did not show any significant interaction with sex. Third, the degree and the relationship of AF risk with metabolic burden may differ in western populations because our study was conducted in an Asian population. Fourth, we incorporated many covariates including lifestyle behaviors, but unavailable confounding and unmeasured factors such as the presence of other inflammatory diseases or the measure of left atrial size could not be fully adjusted. Fifth, the metabolic status may change during the follow-up period and mitigate the risk. Lastly, the causality and underlying mechanistic link between MetS and AF were not answered. Nevertheless, we expanded the previous understanding of the 
association between MetS and AF by showing the biological gradient of metabolic derangements and AF risk in this large population-based study with serial health examination data.

\section{Conclusions}

In this large Asian population-based cohort, the cumulative burden of MetS diagnostic criteria and its components over time has a positive correlation with the risk of incident AF. Given the close association between the cumulative number of total MetS components and the risk of $\mathrm{AF}$, maximal effort to detect and correct metabolic derangements even before the development of MetS might be important to prevent AF and related cardiovascular diseases.

\section{Supplementary Information}

The online version contains supplementary material available at https://doi. org/10.1186/s12933-021-01215-8.

Additional file 1. Additional figure and tables

\section{Abbreviations}

AF: Atrial fibrillation; MI: Myocardial infarction; MetS: Metabolic syndrome; HDL-C: High-density lipoprotein cholesterol; TG: Triglyceride; NHID: National Health Information Database; WC: Waist circumference; HR: Hazard ratio; Cl: Confidence interval.

\section{Acknowledgements}

None.

\section{Authors' contributions}

$\mathrm{HJA}$ had primary responsibility for writing of the article. $\mathrm{KDH}$ and $\mathrm{JHJ}$ carried out data analyses. HJA, KDH, SRL, SK conceived the idea and initiated the analysis plan for the current study. EKC, SO supervised the current study. EKC, GYHL reviewed and commented on draft. All authors coordinated the study and provided comments on drafts of the manuscript, and have revised and approved the manuscript. EKC is the guarantor of this work and, as such, had full access to all the data in the study and takes responsibility for the integrity of the data and the accuracy of the data analysis. All authors read and approved the final manuscript.

\section{Funding}

This work was supported by the Korea Medical Device Development Fund grant funded by the Korea government (the Ministry of Science and ICT, the Ministry of Trade, Industry and Energy, the Ministry of Health \& Welfare, Republic of Korea, the Ministry of Food and Drug Safety) (Project Number: 202013B14), and by the Korea National Research Foundation funded by the Ministry of Education, Science and Technology (Grant 2020R1F1A106740).

\section{Availability of data and materials}

The datasets used and analysed during the current study are available from the corresponding author on reasonable request.

\section{Ethics approval and consent to participate}

The Institutional Review Board at the Seoul National University Hospital (E-2009-091-1157) authorized this study. Informed consent was waived since anonymous and deidentified information was used for analysis.

\section{Consent for publication}

Not applicable.

\section{Competing interests}

HJA, KDH, SRL, JHJ, SK, SO: None to disclose.EKC: Research grants from Bayer, BMS/Pfizer, Biosense Webster, Chong Kun Dang, Daiichi-Sankyo, Samjinpharm, Sanofi-Aventis, Seers Technology, Skylabs, and Yuhan.GYHL: Consultant for Bayer/Janssen, BMS/Pfizer, Medtronic, Boehringer Ingelheim, Novartis, Verseon and Daiichi-Sankyo. Speaker for Bayer, BMS/Pfizer, Medtronic, Boehringer Ingelheim, and Daiichi-Sankyo. No fees are received personally.The external funders and sponsors of the study had no role in study design and conduct of the study; in the collection, analysis, and interpretation of the data; in the preparation, review, or approval of the manuscript; or in the decision to submit the manuscript for publication.

\section{Author details}

${ }^{1}$ Department of Internal Medicine, Seoul National University Hospital, 101 Daehak-ro, Jongno-gu, Seoul 03080, Republic of Korea. ${ }^{2}$ Department of Statistics and Actuarial Science, Soongsil University, Seoul, Republic of Korea. ${ }^{3}$ Department of Internal Medicine, Seoul National University College of Medicine, Seoul, Republic of Korea. ${ }^{4}$ Department of Medical Statistics, College of Medicine, The Catholic University of Korea, Seoul, Republic of Korea. ${ }^{5}$ Liverpool Centre for Cardiovascular Science, University of Liverpool and Liverpool Chest \& Heart Hospital, Liverpool, UK. ${ }^{6}$ Department of Clinical Medicine, Aalborg University, Aalborg, Denmark.

Received: 1 November 2020 Accepted: 9 January 2021

Published online: 19 January 2021

\section{References}

1. Chugh SS, Havmoeller R, Narayanan K, Singh D, Rienstra M, Benjamin EJ, Gillum RF, Kim YH, McAnulty JH Jr, Zheng ZJ, et al. Worldwide epidemiology of atrial fibrillation: a Global Burden of Disease 2010 Study. Circulation. 2014;129(8):837-47.

2. Lee SR, Choi EK, Han KD, Cha MJ, Oh S. Trends in the incidence and prevalence of atrial fibrillation and estimated thromboembolic risk using the CHA2DS2-VASc score in the entire Korean population. Int J Cardiol. 2017;236:226-31.

3. Ruddox V, Sandven I, Munkhaugen J, Skattebu J, Edvardsen T, Otterstad JE. Atrial fibrillation and the risk for myocardial infarction, all-cause mortality and heart failure: a systematic review and meta-analysis. Eur J Prev Cardiol. 2017;24(14):1555-66.

4. Benjamin EJ, Muntner P, Alonso A, Bittencourt MS, Callaway CW, Carson AP, Chamberlain AM, Chang AR, Cheng S, Das SR, et al. Heart Disease and Stroke Statistics-2019 Update: a Report From the American Heart Association. Circulation. 2019;139(10):e56-528.

5. Staerk L, Wang B, Preis SR, Larson MG, Lubitz SA, Ellinor PT, McManus $D D, K o D$, Weng LC, Lunetta KL, et al. Lifetime risk of atrial fibrillation according to optimal, borderline, or elevated levels of risk factors: cohort study based on longitudinal data from the Framingham Heart Study. BMJ. 2018;361:k1453.

6. Chung MK, Eckhardt LL, Chen LY, Ahmed HM, Gopinathannair R, Joglar JA Noseworthy PA, Pack QR, Sanders P, Trulock KM, et al. Lifestyle and risk factor modification for reduction of atrial fibrillation: a scientific statement from the American Heart Association. Circulation. 2020;141(16):e750-72.

7. Joung B. Risk factor management for atrial fibrillation. Korean Circ J. 2019;49(9):794-807.

8. Grundy SM, Cleeman II, Daniels SR, Donato KA, Eckel RH, Franklin BA, Gordon DJ, Krauss RM, Savage PJ, Smith SC Jr, et al. Diagnosis and management of the metabolic syndrome: an American Heart Association/ National Heart, Lung, and Blood Institute Scientific Statement. Circulation. 2005;112(17):2735-52.

9. Expert Panel on Detection E, Treatment of High Blood Cholesterol in A: Executive Summary of The Third Report of The National Cholesterol Education Program (NCEP) Expert Panel on Detection, Evaluation, And Treatment of High Blood Cholesterol In Adults (Adult Treatment Panel III). JAMA 2001, 285(19):2486-2497.

10. Hajhosseiny R, Matthews GK, Lip GY. Metabolic syndrome, atrial fibrillation, and stroke: tackling an emerging epidemic. Heart Rhythm. 2015;12(11):2332-43. 
11. Watanabe H, Tanabe N, Watanabe T, Darbar D, Roden DM, Sasaki S, Aizawa Y. Metabolic syndrome and risk of development of atrial fibrillation: the Niigata preventive medicine study. Circulation. 2008;117(10):1255-60.

12. Choe WS, Choi EK, Han KD, Lee EJ, Lee SR, Cha MJ, Oh S. Association of metabolic syndrome and chronic kidney disease with atrial fibrillation: a nationwide population-based study in Korea. Diabetes Res Clin Pract. 2019;148:14-22.

13. Furukawa S, Fujita T, Shimabukuro M, Iwaki M, Yamada Y, Nakajima Y, Nakayama O, Makishima M, Matsuda M, Shimomura I. Increased oxidative stress in obesity and its impact on metabolic syndrome. J Clin Invest. 2004;114(12):1752-61.

14. Nicolaou VN, Papadakis JE, Karatzis EN, Dermitzaki SI, Tsakiris AK, Skoufas PD. Impact of the metabolic syndrome on atrial size in patients with newonset atrial fibrillation. Angiology. 2007;58(1):21-5.

15. Lee Y, Cha SJ, Park JH, Shin JH, Lim YH, Park HC, Shin J, Kim CK, Park JK. Association between insulin resistance and risk of atrial fibrillation in nondiabetics. Eur J Prev Cardiol. 2020;27(18):1934-41.

16. Wannamethee SG, Lowe GD, Shaper AG, Rumley A, Lennon L, Whincup PH. The metabolic syndrome and insulin resistance: relationship to haemostatic and inflammatory markers in older non-diabetic men. Atherosclerosis. 2005;181(1):101-8.

17. Seyed Ahmadi S, Svensson AM, Pivodic A, Rosengren A, Lind M. Risk of atrial fibrillation in persons with type 2 diabetes and the excess risk in relation to glycaemic control and renal function: a Swedish cohort study. Cardiovasc Diabetol. 2020;19(1):9.

18. Lee HJ, Choi EK, Han KD, Kim DH, Lee E, Lee SR, Oh S, Lip GYH. High variability in bodyweight is associated with an increased risk of atrial fibrillation in patients with type 2 diabetes mellitus: a nationwide cohort study. Cardiovasc Diabetol. 2020;19(1):78.

19. Wang A, Green JB, Halperin JL, Piccini JP Sr. Atrial fibrillation and diabetes mellitus: JACC review topic of the week. J Am Coll Cardiol. 2019;74(8):1107-15.

20. Lip G, Freedman B, De Caterina R, Potpara TS: Stroke prevention in atrial fibrillation: past, present and future. Comparing the guidelines and practical decision-making. Thromb Haemost. 2017;117(7):1230-9.

21. Lee EY, Han K, Kim DH, Park YM, Kwon HS, Yoon KH, Kim MK, Lee SH. Exposure-weighted scoring for metabolic syndrome and the risk of myocardial infarction and stroke: a nationwide population-based study. Cardiovasc Diabetol. 2020;19(1):153.

22. Choi EK. Cardiovascular research using the korean national health information database. Korean Circ J. 2020;50(9):754-72.

23. Cheol Seong S, Kim YY, Khang YH, Heon Park J, Kang HJ, Lee H, Do CH, Song JS, Hyon Bang J, Ha S, et al. Data resource profile: the national health information database of the national health insurance service in South Korea. Int J Epidemiol. 2017;46(3):799-800.

24. Seo MH, Lee WY, Kim SS, Kang JH, Kang JH, Kim KK, Kim BY, Kim YH, Kim WJ, Kim EM, et al. 2018 Korean Society for the study of obesity guideline for the management of obesity in Korea. J Obes Metab Syndr. 2019;28(1):40-5.

25. Lee SR, Choi EK, Kwon S, Han KD, Jung JH, Cha MJ, Oh S, Lip GYH. Effectiveness and safety of contemporary oral anticoagulants among asians with nonvalvular atrial fibrillation. Stroke. 2019;50(8):2245-9.

26. Chamberlain AM, Agarwal SK, Ambrose M, Folsom AR, Soliman EZ, Alonso A. Metabolic syndrome and incidence of atrial fibrillation among blacks and whites in the Atherosclerosis Risk in Communities (ARIC) Study. Am Heart J. 2010;159(5):850-6.

27. Nystrom PK, Carlsson AC, Leander K, de Faire U, Hellenius ML, Gigante B. Obesity, metabolic syndrome and risk of atrial fibrillation: a Swedish, prospective cohort study. PLOS ONE. 2015;10(5):e0127111.

28. Tanner RM, Baber U, Carson AP, Voeks J, Brown TM, Soliman EZ, Howard VJ, Muntner P. Association of the metabolic syndrome with atrial fibrillation among United States adults (from the REasons for Geographic and Racial Differences in Stroke [REGARDS] Study). Am J Cardiol. 2011;108(2):227-32.

29. Vyssoulis G, Karpanou E, Adamopoulos D, Kyvelou SM, Tzamou V, Michaelidis A, Stefanadis C. Metabolic syndrome and atrial fibrillation in patients with essential hypertension. Nutr Metab Cardiovasc Dis. 2013;23(2):109-14.

30. Georgakopoulos C, Vlachopoulos C, Lazaros G, Tousoulis D. Biomarkers of atrial fibrillation in metabolic syndrome. Curr Med Chem. 2019;26(5):898-908
31. Alonso A, Yin X, Roetker NS, Magnani JW, Kronmal RA, Ellinor PT, Chen LY, Lubitz SA, McClelland RL, McManus DD, et al. Blood lipids and the incidence of atrial fibrillation: the multi-ethnic study of atherosclerosis and the Framingham Heart Study. J Am Heart Assoc. 2014;3(5):e001211.

32. Li W, Song F, Wang X, Wang D, Chen D, Yue W, Zhang H, Wang Z, Lu Z. Relationship between metabolic syndrome and its components and cardiovascular disease in middle-aged and elderly Chinese population: a national cross-sectional survey. BMJ Open. 2019;9(8):e027545.

33. Lundman P, Eriksson MJ, Stuhlinger M, Cooke JP, Hamsten A, Tornvall P. Mild-to-moderate hypertriglyceridemia in young men is associated with endothelial dysfunction and increased plasma concentrations of asymmetric dimethylarginine. J Am Coll Cardiol. 2001;38(1):111-6.

34. Sacks FM, Hermans MP, Fioretto P, Valensi P, Davis T, Horton E, Wanner C, Al-Rubeaan K, Aronson R, Barzon I, et al. Association between plasma triglycerides and high-density lipoprotein cholesterol and microvascular kidney disease and retinopathy in type 2 diabetes mellitus: a global casecontrol study in 13 countries. Circulation. 2014;129(9):999-1008.

35. Shankar A, Mitchell P, Rochtchina E, Wang JJ. The association between circulating white blood cell count, triglyceride level and cardiovascular and all-cause mortality: population-based cohort study. Atherosclerosis. 2007;192(1):177-83.

36. Saltiel AR, Kahn CR. Insulin signalling and the regulation of glucose and lipid metabolism. Nature. 2001;414(6865):799-806.

37. Wong CY, O'Moore-Sullivan T, Leano R, Byrne N, Beller E, Marwick TH. Alterations of left ventricular myocardial characteristics associated with obesity. Circulation. 2004;110(19):3081-7.

38. Horio T, Miyazato J, Kamide K, Takiuchi S, Kawano Y. Influence of low high-density lipoprotein cholesterol on left ventricular hypertrophy and diastolic function in essential hypertension. Am J Hypertens. 2003;16(11 Pt 1):938-44.

39. Healey JS, Connolly SJ. Atrial fibrillation: hypertension as a causative agent, risk factor for complications, and potential therapeutic target. Am J Cardiol. 2003;91(10A):9G-14G.

40. Echahidi N, Mohty D, Pibarot P, Despres JP, O'Hara G, Champagne J, Philippon F, Daleau P, Voisine P, Mathieu P. Obesity and metabolic syndrome are independent risk factors for atrial fibrillation after coronary artery bypass graft surgery. Circulation. 2007;116(11 Suppl):1213-219.

41. Chan YH, Chang GJ, Lai YJ, Chen WJ, Chang SH, Hung LM, Kuo CT, Yeh YH. Atrial fibrillation and its arrhythmogenesis associated with insulin resistance. Cardiovasc Diabetol. 2019;18(1):125

42. Chung MK, Martin DO, Sprecher D, Wazni O, Kanderian A, Carnes CA, Bauer JA, Tchou PJ, Niebauer MJ, Natale A, et al. C-reactive protein elevation in patients with atrial arrhythmias: inflammatory mechanisms and persistence of atrial fibrillation. Circulation. 2001;104(24):2886-91.

43. Rohrer $L$, Hersberger M, von Eckardstein A. High density lipoproteins in the intersection of diabetes mellitus, inflammation and cardiovascular disease. Curr Opin Lipidol. 2004;15(3):269-78.

44. Wang Z, Wang B, Li X, Zhang S, Wu S, Xia Y. Metabolic syndrome, highsensitivity $C$-reactive protein levels and the risk of new-onset atrial fibrillation: results from the Kailuan Study. Metabolism and Cardiovascular Diseases: Nutrition; 2020.

45. O'Neill S, O'Driscoll L. Metabolic syndrome: a closer look at the growing epidemic and its associated pathologies. Obes Rev. 2015:16(1):1-12.

46. Saklayen MG. The global epidemic of the metabolic syndrome. Curr Hypertens Rep. 2018;20(2):12.

47. Wolf PA, Dawber TR, Thomas HE Jr, Kannel WB. Epidemiologic assessment of chronic atrial fibrillation and risk of stroke: the Framingham study. Neurology. 1978;28(10):973-7.

48. Park S, Lee S, Kim Y, Lee Y, Kang MW, Han K, Han SS, Lee H, Lee JP, Joo KW, et al. Altered risk for cardiovascular events with changes in the metabolic syndrome status: a nationwide population-based study of approximately 10 million persons. Ann Intern Med. 2019;171(12):875-84.

49. Gorenek B, Pelliccia A, Benjamin EJ, Boriani G, Crijns HJ, Fogel RI, Van Gelder IC, Halle M, Kudaiberdieva G, Lane DA, et al. European Heart Rhythm Association (EHRA)/European Association of Cardiovascular Prevention and Rehabilitation (EACPR) position paper on how to prevent atrial fibrillation endorsed by the Heart Rhythm Society (HRS) and Asia Pacific Heart Rhythm Society (APHRS). Europace. 2017;19(2):190-225.

50. Heo NJ, Rhee SY, Waalen J, Steinhubl S. Chronic kidney disease and undiagnosed atrial fibrillation in individuals with diabetes. Cardiovasc Diabetol. 2020;19(1):157. 
51. Hindricks G, Potpara T, Dagres N, Arbelo E, Bax JJ, Blomstrom-Lundqvist C, Boriani G, Castella M, Dan GA, Dilaveris PE, et al. ESC Guidelines for the diagnosis and management of atrial fibrillation developed in collaboration with the European Association of Cardio-Thoracic Surgery (EACTS). Eur Heart J 2020;ehaa612. https://doi.org/10.1093/eurheartj/ehaa612.

\section{Publisher's Note}

Springer Nature remains neutral with regard to jurisdictional claims in published maps and institutional affiliations.
Ready to submit your research? Choose BMC and benefit from:

- fast, convenient online submission

- thorough peer review by experienced researchers in your field

- rapid publication on acceptance

- support for research data, including large and complex data types

- gold Open Access which fosters wider collaboration and increased citations

- maximum visibility for your research: over $100 \mathrm{M}$ website views per year

At BMC, research is always in progress.

Learn more biomedcentral.com/submissions 